\title{
Cerebral Metabolic Intermediate Response following Severe Canine Intrauterine Growth Retardation
}

\author{
ROBERT M. KLIEGMAN \\ Case Western Reserve University, School of Medicine, Department of Pediatrics, Rainbow Babies and Childrens \\ Hospital, Cleveland, Ohio 44106
}

\begin{abstract}
The effect of intrauterine growth retardation and neonatal hypoglycemia on cerebral metabolic intermediates were determined in newborn dogs subjected to 5 days of maternal canine starvation (MCS) before birth. Birth weight was reduced $23 \%$ (232 \pm 6 versus $300 \pm 10$ g). Circulating blood glucose was reduced after $3 \mathrm{~h}$ of neonatal fasting in MCS pups $(2.7 \pm 0.4 \pm$ versus $5.7 \pm$ $1.1 \mathrm{mM}$ ). Cerebral cortical levels of glucose were also reduced at this time. Cerebral glucose-6-phosphate was not altered; nonetheless fructose-6-phosphate was lower in MCS pups at 6 and $9 \mathrm{~h}$, while fructose 1,6-diphosphate appeared elevated at $3 \mathrm{~h}$. These data suggest that cerebral glycolytic activity may be increased by increased activity of phosphofructokinase. Cerebral glutamine appeared reduced in fasting MCS pups at 3,6 , and $8 \mathrm{~h}$ of age. A considerable disturbance of the adenine nucleotide pool was noted between 3-9 $\mathrm{h}$ in MCS pups; while the cerebral energy reserve was diminished in MCS pups between 3$24 \mathrm{~h}$. The data of reduced cerebral energy status and reserve suggest that cerebral energy production was diminished. Although glucose levels were low at $3 \mathrm{~h}$, subsequent recovery was not immediate as adenine-nucleotides remained low beyond the period of hypoglycemia. The combined effects of intrauterine growth retardation and transient neonatal hypoglycemia appear to result in reduced cerebral oxidative metabolism; this occurs despite an apparent enhanced utilization of alternate fuels. (Pediatr Res 20: $662-667,1986$ )
\end{abstract}

\section{Abbreviations}

MCS, maternal canine starvation

FFA, free-fatty acids

G6P, glucose-6-phosphate

F6P, fructose-6-phosphate

FDP, fructose-1,6-diphosphate

$\alpha \mathrm{KG}, \alpha$-ketoglutarate

OAA, oxaloacetate

PEP, phosphoenolpyruvate

UDPGlu, uridine diphosphoglucose

PCr, creatine phosphate

Maternal nutritional deprivation results in intrauterine growth retardation in various mammalian species $(1,2)$. The metabolic adaptation following birth among humans and dogs with intra-

Received June 3, 1985; accepted March 10, 1986

Reprints R. M. Kliegman, M.D., Rainbow Babies and Childrens Hospital, 2101 Adelbert Road, Cleveland, $\mathrm{OH} 44106$.

Supported by NICHD Grant HD 05740 . uterine growth retardation is abnormal, and is characterized by fasting hypoglycemia, attenuated FFA levels, and increased plasma levels of gluconeogenic amino acids (3-5).

Symptomatic fasting hypoglycemia may have adverse effects on the developing central nervous system (6). Hypoglycemia, combined with the adverse effects of intrauterine growth retardation, may seriously affect fetal brain growth and future brain function. Previous studies in our laboratory among mildly growth retarded newborn dogs demonstrated that the cerebral cortical metabolic state appeared unperturbed in the fetus at the time of birth (7). However, cerebral cortical metabolic changes in growth retarded newborn dogs were most marked with the development of fasting neonatal hypoglycemia after birth. Brain glucose and glycogen content and the calculated energy reserve were diminished during the 24 -h period following birth. Nonetheless, cerebral ATP levels were unaltered. Cerebral amino acid patterns suggested that the glutamate group of amino acids were functioning as alternate fuels and were being oxidized to support brain energy metabolism.

As 3 days of maternal nutritional deprivation only resulted in a small reduction of fetal growth, we have extended the period of nutritional deprivation to 5 days. This extended period of nutrient withdrawal has resulted in marked intrauterine growth retardation, and has produced circulating substrate perturbations which parallel those observed in the human growth-retarded infant (5). The present report concerns the effects of intrauterine growth retardation on cerebral energy metabolism. These data suggest that severe intrauterine growth retardation and subsequent neonatal hypoglycemia significantly reduce brain energy production, even beyond the period of diminished glucose levels. The results of fasting circulating fuel turnover and hepatic intermediary metabolism from these same newborn dogs have been reported previously $(5,6)$.

\section{METHODS}

Materials. All enzymes used were purchased from Sigma, St. Louis, MO.

Animals. Pregnant beagle dogs were maintained in kennels and fed a standard canine diet. Before delivery, six mothers were fasted overnight $(18 \mathrm{~h})$ providing a control group, while eight were fasted for 5 days providing the MCS group. Cesarean section was done at term $(60 \pm 2$ days). The newborn pups were immediately transferred to an incubator maintained at $37^{\circ} \mathrm{C}$ with relative humidity of $70 \%(5,8)$. The newborn pups were fasted throughout the study period in both groups. Litter size in the control group was $5.3 \pm 0.5$ (mean \pm SEM) and $4.6 \pm 0.8$ in the MCS group.

The number of analyses varies at different time points because we were unable to obtain sufficient quantities of blood or tissue for every analysis from each mother and pup. 
Experimental design. Immediately before a term Cesarean section, intravenous anesthesia (4 $\mathrm{mg} / \mathrm{kg}$ chlorpromazine) was given to the mother. Lidocaine ( $2 \%$ ) was also used to anesthetize the incision area (5). Paired blood samples were taken from the mother and, immediately after delivery, from one or two fetuses. The newborn pups were permitted to stabilize, were weighed, and had umbilical arterial and venous catheters (3.5 French Argyle, St. Louis, MO) placed atraumatically. This was to facilitate blood withdrawal and quantitation of turnover data as reported previously (5).

Pups were studied after 0 (fetal), 3, 6, 9, and $24 \mathrm{~h}$ of fasting. Because the immediate postnatal period is one of flux with major metabolic perturbations occurring at different time periods within the first $24 \mathrm{~h}$ of life, we studied both control and MCS pups at these four different time periods. Because of these postnatal changes, we would not expect to observe similar brain alterations at each time interval investigated.

Immediately at birth and at 3,6, 9, and $24 \mathrm{~h}$ of age, the pups from each litter were sacrificed by a guillotine designed to transect the cranium exposing the cortex. The entire cerebral cortex was freeze-clamped at the temperature of liquid nitrogen in less than $3 \mathrm{sec}$ with heavy aluminum blocks. These blocks were previously cooled to the temperature of liquid nitrogen. In addition, they were placed at the end of bone clamps to ensure immediate flattening of the cortex. This avoids differential cooling of the center of the sample compared with the external surface. Thickness of frozen samples was between 1 and $2 \mathrm{~mm}$. Redox state, energy charge, and ATP levels in the normal pup group do not demonstrate any evidence for brain ischemia (9-11). The tissues were stored at $-80^{\circ} \mathrm{C}$ until analyzed.

\section{ANALYSES}

The frozen cerebral cortex was pulverized to a fine powder at the temperature of dry ice. Extraction and homogenization were performed as reported before at $0^{\circ} \mathrm{C}(7)$. Immediately following acid extraction and rapid neutralization, aliquots were divided and stored at $-80^{\circ} \mathrm{C}$. Phosphocreatine, ATP, ADP, and AMP were analyzed within $1 \mathrm{wk}$ of storage of the frozen tissue and within 1 wk of extraction and neutralization. These periods of storage have not resulted in a decrement of ATP levels among neonatal canine brain samples. Our results for ATP in normal fetal and neonatal dogs are not different from those values reported in newborn dogs and rodents $(9-11)$. Thereafter, glycogen, glucose, UDP glucose, G6P, F6P, FDP, phosphoenolpyruvate, pyruvate, lactate, citrate, $\alpha \mathrm{KG}$, malate, aspartate, alanine, glutamate, glutamine, and ammonia were assayed as reported previously (7). Cerebral cytoplasmic NAD/NADH ratio, oxaloacetate, and energy charge were calculated as described before (7). All analyses were performed in duplicate. The interassay variation was $5-10 \%$, while the intraassay was less than $5 \%$.

\section{STATISTICAL ANALYSES}

Figure or tabular notations are the mean \pm SEM. Sample size is depicted in Tables 1-4. Tissue metabolites are expressed as $\mu \mathrm{mol} / \mathrm{g}$ tissue wet weight. Circulating fuels are expressed as $\mathrm{mM}$. Standard calculator programs were used for Student's $t$ test analyses of data between the two groups. Due to multiple analyses at five time epochs, a $p$ value of less than 0.05 will be accepted to avoid a type 1 error. Values of 0.05 will be discussed only if part of a trend, e.g. $p$ values of 0.01 were present before or following that epoch. Due to normal changes with age in the 1st day of life, the major comparisons are made between experimental and control groups at the same time period. Longitudinal data analyses are expressed in the text.

\section{RESULTS}

The birth weight of the MCS pups was $232 \pm 6(n=37)$, while control pups were significantly heavier, weighing $300 \pm 10 \mathrm{~g}(n$ $=32)(p=0.001)$. Pups from both groups behaved the same and remained pink and active throughout the study period of fasting which ranged from 3 to $24 \mathrm{~h}$.

Circulating substrate concentrations. At the time of birth, maternal blood glucose $(3.2 \pm 0.4$ versus $4.1 \pm 0.2 \mathrm{mM})(p<$ $0.05)$ appeared lower while total ketones $(5.8 \pm 1.4$ versus $0.4 \pm$ $0.1 \mathrm{mM})(p<0.005)$ were significantly higher following maternal canine starvation (5). Blood lactate, FFA, and glycerol were not affected in the mothers. Fetal blood glucose $(3.6 \pm 0.19$ versus $2.8 \pm 0.48 \mathrm{mM}$ in MCS), lactate, FFA, and glycerol were not changed; while fetal ketonemia appeared augmented in the MCS pups $(3.3 \pm 0.7$ versus $0.2 \pm 0.1 \mathrm{mM})(p<0.05)(5)$.

After birth glucose increased in control pups but did not rise in MCS pups, and blood glucose levels after $3 \mathrm{~h}$ of fasting were lower $(2.7 \pm 0.4$ versus $5.7 \pm 1.1 \mathrm{mM})(p<0.05)(5)$. Thereafter glucose values in MCS pups increased and were equivalent to control pups. Ketone levels became lower after birth and were not altered in the fasted neonates from either group, remaining less than $0.25 \mathrm{mM}$. However, plasma FFA levels appeared to be decreased in the MCS pups at $3 \mathrm{~h}$ of age $(0.50 \pm 0.06$ versus 0.70 $\pm 0.07 \mathrm{mM})(p<0.05)$. Furthermore circulating glycerol levels were reduced in MCS pups after 3,6, and $9 \mathrm{~h}$ of neonatal fasting (5).

Cerebral Metabolism following MCS. Glycolysis (Table 1). In control pups cerebral glucose levels increased between birth and $3 \mathrm{~h}(p<0.02)$ and remained constant during the remaining fasting period. At birth glucose values in the cerebral cortex of MCS pups were similar to control values. However at $3 \mathrm{~h}$ after birth cerebral glucose concentrations were significantly lower in the MCS pups. At this time UDP-glucose levels were also lower in MCS pups. Furthermore between 0 and $3 \mathrm{~h}$ of age in control pups, cerebral glycogen content appeared to be increased $(p<$ 0.05 ) while glycogen levels did not increase between 0 and $3 \mathrm{~h}$ in pups of starved mothers. Glycogen content was not reduced in MCS pups compared with age matched controls at 3,6, or 9 $\mathrm{h}$ of age. Nonetheless after $24 \mathrm{~h}$ of fasting MCS pups appeared to have lower cerebral cortical glycogen levels than control pups.

G6P concentrations were not different between the pup groups; however F6P levels were diminished at birth and at 6 and $9 \mathrm{~h}$ of age in the fasted MCS newborn pups compared with age-matched control pups. FDP was only determined at 0 and $3 \mathrm{~h}$ because of limited tissue remaining in which to perform this assay. At birth FDP levels were similar $(0.0066 \pm 0.0010$ versus $0.0074 \pm 0.0011$ $\mu \mathrm{mol} / \mathrm{g}$ ). At $3 \mathrm{~h}$ of age cerebral FDP levels in MCS pups increased; at this time FDP concentrations appeared greater in the MCS pups $(0.0120 \pm 0.0021$ versus $0.0081 \pm 0.0011)(p<0.05)$. Phosphoenolpyruvate and pyruvate levels were unaltered while lactate levels appeared to be diminished in MCS pups compared with age matched control pups at 3 and $6 \mathrm{~h}$ of age.

Cerebral Krebs cycle intermediates (Table 2). Cerebral cortical levels of citrate were not affected during the period of neonatal hypoglycemia or throughout the $24 \mathrm{~h}$ of fasting. $\alpha \mathrm{KG}$ did not demonstrate differences between groups at the neonatal time periods tested. Cortical levels of malate were diminished at 3,6, and $9 \mathrm{~h}$ in MCS pups compared with the age-matched controls, while the calculated oxaloacetate concentration was only augmented in the MCS at $0 \mathrm{~h}$.

Cerebral amino acids (Table 3). Alanine concentrations in the cortex appeared to be diminished in the MCS pups at $3 \mathrm{~h}$ of age compared with age-matched control pups. In contrast, cerebral cortical aspartate levels were augmented at 3 and $6 \mathrm{~h}$ of age in MCS pups. Glutamate was transiently elevated following MCS at $9 \mathrm{~h}$. More consistently, glutamine concentrations were diminished after 3,6, and $9 \mathrm{~h}$ of neonatal fasting in MCS pups compared with age-matched control pups. Cerebral ammonia content was not affected by MCS or by any duration of neonatal fasting.

Cerebral energy state (Table 4). At the time of birth, fetal energy status, as determined by creatine phosphate, ATP, the 
Table 1. Cerebral glycolytic intermediates (mean $\pm S E M: \mu m o l / g$ )

\begin{tabular}{|c|c|c|c|c|c|c|}
\hline & & $0 \mathrm{~h}$ & $3 \mathrm{~h}$ & $6 \mathrm{~h}$ & $9 \mathrm{~h}$ & $24 \mathrm{~h}$ \\
\hline Glucose & $\begin{array}{l}\mathrm{C}^{*} \\
\mathrm{MCS} \dagger\end{array}$ & $\begin{array}{l}1.87 \pm 0.28 \\
1.55 \pm 0.33\end{array}$ & $\begin{array}{l}3.78 \pm 0.71 \\
1.72 \pm 0.32 \ddagger\end{array}$ & $\begin{array}{l}3.09 \pm 0.59 \\
2.50 \pm 0.61\end{array}$ & $\begin{array}{l}3.56 \pm 0.56 \\
3.51 \pm 0.90\end{array}$ & $\begin{array}{l}2.48 \pm 0.35 \\
1.53 \pm 0.56\end{array}$ \\
\hline UDPGlu & $\begin{array}{l}\mathrm{C} \\
\mathrm{MCS}\end{array}$ & $\begin{array}{l}0.096 \pm 0.002 \\
0.091 \pm 0.004\end{array}$ & $\begin{array}{l}0.103 \pm 0.005 \\
0.080 \pm 0.004 \ddagger\end{array}$ & $\begin{array}{l}0.092 \pm 0.010 \\
0.074 \pm 0.007\end{array}$ & $\begin{array}{l}0.096 \pm 0.010 \\
0.091 \pm 0.004\end{array}$ & $\begin{array}{l}0.088 \pm 0.002 \\
0.087 \pm 0.006\end{array}$ \\
\hline Glycogen & $\begin{array}{l}\mathrm{C} \\
\mathrm{MCS}\end{array}$ & $\begin{array}{l}1.66 \pm 0.16 \\
2.04 \pm 0.46\end{array}$ & $\begin{array}{l}2.42 \pm 0.35 \\
2.23 \pm 0.26\end{array}$ & $\begin{array}{l}2.40 \pm 0.37 \\
2.34 \pm 0.34\end{array}$ & $\begin{array}{l}2.50 \pm 0.60 \\
2.14 \pm 0.21\end{array}$ & $\begin{array}{l}2.46 \pm 0.24 \\
1.82 \pm 0.09 \S\end{array}$ \\
\hline G6P & $\begin{array}{l}\mathrm{C} \\
\mathrm{MCS}\end{array}$ & $\begin{array}{l}0.088 \pm 0.013 \\
0.106 \pm 0.009\end{array}$ & $\begin{array}{l}0.126 \pm 0.016 \\
0.134 \pm 0.013\end{array}$ & $\begin{array}{l}0.109 \pm 0.007 \\
0.107 \pm 0.016\end{array}$ & $\begin{array}{l}0.091 \pm 0.006 \\
0.123 \pm 0.023\end{array}$ & $\begin{array}{l}0.098 \pm 0.010 \\
0.110 \pm 0.018\end{array}$ \\
\hline F6P & $\begin{array}{l}\mathrm{C} \\
\mathrm{MCS}\end{array}$ & $\begin{array}{l}0.066 \pm 0.017 \\
0.029 \pm 0.005 \S\end{array}$ & $\begin{array}{l}0.047 \pm 0.008 \\
0.029 \pm 0.006\end{array}$ & $\begin{array}{l}0.047 \pm 0.009 \\
0.019 \pm 0.004 \ddagger\end{array}$ & $\begin{array}{l}0.050 \pm 0.006 \\
0.018 \pm 0.002 \ddagger\end{array}$ & $\begin{array}{l}0.036 \pm 0.008 \\
0.024 \pm 0.008\end{array}$ \\
\hline PEP & $\begin{array}{l}\mathrm{C} \\
\mathrm{MCS}\end{array}$ & $\begin{array}{l}0.098 \pm 0.011 \\
0.091 \pm 0.009\end{array}$ & $\begin{array}{l}0.091 \pm 0.001 \\
0.112 \pm 0.018\end{array}$ & $\begin{array}{l}0.093 \pm 0.002 \\
0.097 \pm 0.012\end{array}$ & $\begin{array}{l}0.084 \pm 0.004 \\
0.086 \pm 0.013\end{array}$ & $\begin{array}{l}0.105 \pm 0.021 \\
0.077 \pm 0.007\end{array}$ \\
\hline Pyruvate & $\begin{array}{l}\mathrm{C} \\
\mathrm{MCS}\end{array}$ & $\begin{array}{l}0.310 \pm 0.018 \\
0.326 \pm 0.019\end{array}$ & $\begin{array}{l}0.232 \pm 0.012 \\
0.208 \pm 0.022\end{array}$ & $\begin{array}{l}0.207 \pm 0.012 \\
0.204 \pm 0.009\end{array}$ & $\begin{array}{l}0.225 \pm 0.014 \\
0.265 \pm 0.022\end{array}$ & $\begin{array}{l}0.228 \pm 0.014 \\
0.221 \pm 0.023\end{array}$ \\
\hline Lactate & $\begin{array}{l}\mathrm{C} \\
\mathrm{MCS}\end{array}$ & $\begin{array}{l}3.47 \pm 0.73 \\
2.88 \pm 0.51\end{array}$ & $\begin{array}{l}2.35 \pm 0.34 \\
1.66 \pm 0.18\end{array}$ & $\begin{array}{l}2.43 \pm 0.30 \\
1.67 \pm 0.16 \S\end{array}$ & $\begin{array}{l}2.36 \pm 0.24 \\
2.33 \pm 0.48\end{array}$ & $\begin{array}{l}1.54 \pm 0.22 \\
1.74 \pm 0.31\end{array}$ \\
\hline $\begin{array}{l}\text { No. studied } \\
\text { Control } \\
\text { MCS }\end{array}$ & & $\begin{array}{l}6 \\
7\end{array}$ & $\begin{array}{l}6 \\
9\end{array}$ & $\begin{array}{l}6 \\
7\end{array}$ & $\begin{array}{l}6 \\
5\end{array}$ & $\begin{array}{l}6 \\
5\end{array}$ \\
\hline
\end{tabular}

* Control.

$\dagger$ Prior MCS.

$\ddagger p<0.01$.

$\S p<0.05$.

Table 2. Cerebral Kreb's cycle intermediates (mean \pm SEM: $\mu \mathrm{mol} / \mathrm{g}$ )

\begin{tabular}{|c|c|c|c|c|c|c|}
\hline & & $0 \mathrm{~h}$ & $3 \mathrm{~h}$ & $6 \mathrm{~h}$ & $9 \mathrm{~h}$ & $24 \mathrm{~h}$ \\
\hline \multirow[t]{2}{*}{ Citrate } & $\mathrm{C}^{*}$ & $0.276 \pm 0.012$ & $0.250 \pm 0.013$ & $0.248 \pm 0.010$ & $0.285 \pm 0.008$ & $0.252 \pm 0.017$ \\
\hline & $\mathrm{MCS} \dagger$ & $0.245 \pm 0.018$ & $0.207 \pm 0.022$ & $0.244 \pm 0.050$ & $0.216 \pm 0.043$ & $0.202 \pm 0.029$ \\
\hline \multirow[t]{2}{*}{$\alpha \mathrm{KG}$} & $\mathrm{C}$ & $0.074 \pm 0.008$ & $0.085 \pm 0.012$ & $0.089 \pm 0.007$ & $0.090 \pm 0.003$ & $0.087 \pm 0.007$ \\
\hline & MCS & $0.094 \pm 0.003 \ddagger$ & $0.092 \pm 0.009$ & $0.087 \pm 0.009$ & $0.102 \pm 0.007$ & $0.079 \pm 0.006$ \\
\hline \multirow[t]{2}{*}{ Malate } & C & $0.185 \pm 0.023$ & $0.203 \pm 0.029$ & $0.196 \pm 0.022$ & $0.263 \pm 0.012$ & $0.177 \pm 0.019$ \\
\hline & $\mathrm{MCS}$ & $0.185 \pm 0.012$ & $0.119 \pm 0.007 \S$ & $0.135 \pm 0.014 \ddagger$ & $0.147 \pm 0.010 \S$ & $0.132 \pm 0.019$ \\
\hline \multirow[t]{2}{*}{ OAA } & C & $0.0013 \pm 0.0001$ & $0.0021 \pm 0.0005$ & $0.0024 \pm 0.0002$ & $0.0027 \pm 0.0002$ & $0.0027 \pm 0.0004$ \\
\hline & MCS & $0.0022 \pm 0.0001 \|$ & $0.0025 \pm 0.0002$ & $0.0031 \pm 0.0007$ & $0.0025 \pm 0.0003$ & $0.0019 \pm 0.0002$ \\
\hline \multicolumn{7}{|l|}{ No. studied } \\
\hline Control & & 6 & 6 & 6 & 6 & 6 \\
\hline MCS & & 7 & 9 & 7 & 5 & 5 \\
\hline
\end{tabular}

* Control.

$\dagger$ Prior MCS.

$\ddagger p<0.05$.

$\S p<0.001$.

$\| p<0.01$.

total adenine nucleotide pool size, the energy charge, and energy reserve, was not significantly affected by MCS. However, after birth and with the development of fasting neonatal hypoglycemia, cerebral energy metabolism was altered in the MCS pups. $\mathrm{PCr}$ levels were diminished at 3,6 , and $9 \mathrm{~h}$, while cerebral cortical ATP was diminished at 6 and $9 \mathrm{~h}$ of age in MCS pups. Furthermore ADP was diminished at 3,6 , and $9 \mathrm{~h}$ of age, while AMP appeared to be augmented at 3 and $6 \mathrm{~h}$ in MCS pups compared with age matched control pups. These alterations resulted in a net reduction of the total adenine nucleotide pool in MCS pups during hypoglycemia $(3 \mathrm{~h})$ and the period of recovery at 6 and $9 \mathrm{~h}$ of age. Although the ratio of adenine nucleotides, expressed in the energy charge, was not altered, the sum of energy yielding compounds, expressed as the energy reserve, was diminished following MCS during hypoglycemia (3 h) and recovery at 6, 9, and $24 \mathrm{~h}$ of age. In addition, the cerebral cytoplasmic redox state was more oxidized at $3 \mathrm{~h}$ of age compared to age-matched pups born to normal mothers. 
Table 3. Cerebral amino acids and ammonia (mean $\pm S E M: \mu \mathrm{mol} / \mathrm{g}$ )

\begin{tabular}{|c|c|c|c|c|c|c|}
\hline & & $0 \mathrm{~h}$ & $3 \mathrm{~h}$ & $6 \mathrm{~h}$ & $9 \mathrm{~h}$ & $24 \mathrm{~h}$ \\
\hline Alanine & $\begin{array}{l}\mathrm{C}^{*} \\
\mathrm{MCS} \dagger\end{array}$ & $\begin{array}{l}0.771 \pm 0.070 \\
0.629 \pm 0.048\end{array}$ & $\begin{array}{l}0.748 \pm 0.065 \\
0.542 \pm 0.064 \ddagger\end{array}$ & $\begin{array}{l}0.555 \pm 0.084 \\
0.485 \pm 0.035\end{array}$ & $\begin{array}{l}0.540 \pm 0.039 \\
0.552 \pm 0.069\end{array}$ & $\begin{array}{l}0.678 \pm 0.095 \\
0.592 \pm 0.066\end{array}$ \\
\hline Aspartate & $\begin{array}{l}\mathrm{C} \\
\mathrm{MCS}\end{array}$ & $\begin{array}{l}0.550 \pm 0.042 \\
0.658 \pm 0.051\end{array}$ & $\begin{array}{l}0.602 \pm 0.036 \\
0.792 \pm 0.045 \S\end{array}$ & $\begin{array}{l}0.593 \pm 0.041 \\
0.767 \pm 0.068\end{array}$ & $\begin{array}{l}0.624 \pm 0.069 \\
0.787 \pm 0.041\end{array}$ & $\begin{array}{l}0.678 \pm 0.044 \\
0.748 \pm 0.029\end{array}$ \\
\hline Glutamate & $\begin{array}{l}\mathrm{C} \\
\mathrm{MCS}\end{array}$ & $\begin{array}{l}4.44 \pm 0.43 \\
4.52 \pm 0.46\end{array}$ & $\begin{array}{l}3.98 \pm 0.46 \\
4.43 \pm 0.18\end{array}$ & $\begin{array}{l}3.40 \pm 0.37 \\
3.54 \pm 0.26\end{array}$ & $\begin{array}{l}3.20 \pm 0.27 \\
4.93 \pm 0.47 \S\end{array}$ & $\begin{array}{l}3.49 \pm 0.37 \\
4.88 \pm 0.62\end{array}$ \\
\hline Glutamine & $\begin{array}{l}\mathrm{C} \\
\mathrm{MCS}\end{array}$ & $\begin{array}{l}9.98 \pm 0.29 \\
9.54 \pm 0.57\end{array}$ & $\begin{aligned} 10.06 & \pm 0.47 \\
8.24 & \pm 0.45 \|\end{aligned}$ & $\begin{array}{l}8.98 \pm 0.19 \\
7.77 \pm 0.25 \ddagger\end{array}$ & $\begin{array}{l}9.72 \pm 0.31 \\
8.01 \pm 0.54 \|\end{array}$ & $\begin{array}{l}7.71 \pm 0.13 \\
8.53 \pm 0.62\end{array}$ \\
\hline Ammonia & $\begin{array}{l}\mathrm{C} \\
\mathrm{MCS}\end{array}$ & $\begin{array}{l}0.462 \pm 0.056 \\
0.473 \pm 0.060\end{array}$ & $\begin{array}{l}0.460 \pm 0.025 \\
0.499 \pm 0.051\end{array}$ & $\begin{array}{l}0.470 \pm 0.040 \\
0.473 \pm 0.080\end{array}$ & $\begin{array}{l}0.562 \pm 0.061 \\
0.514 \pm 0.065\end{array}$ & $\begin{array}{l}0.519 \pm 0.062 \\
0.578 \pm 0.082\end{array}$ \\
\hline
\end{tabular}

* Control.

$\uparrow$ Prior MCS.

$\ddagger p<0.05$.

$\S p<0.01$.

$\| p<0.02$.

Table 4. Cerebral high energy phosphate compounds (mean \pm SEM: $\mu \mathrm{mol} / \mathrm{g}$ )

\begin{tabular}{|c|c|c|c|c|c|c|}
\hline & & $0 \mathrm{~h}$ & $3 \mathrm{~h}$ & $6 \mathrm{~h}$ & $9 \mathrm{~h}$ & $24 \mathrm{~h}$ \\
\hline \multirow[t]{2}{*}{$\mathrm{PCr}$} & $\mathrm{C}^{*}$ & $9.27 \pm 1.23$ & $12.43 \pm 1.82$ & $14.67 \pm 1.64$ & $16.09 \pm 1.78$ & $11.27 \pm 1.41$ \\
\hline & $\mathrm{MCS}_{\dagger}$ & $7.69 \pm 0.74$ & $7.12 \pm 0.75 \|$ & $8.33 \pm 0.699$ & $7.50 \pm 1.09^{* *}$ & $9.76 \pm 2.16$ \\
\hline \multirow[t]{2}{*}{ ATP } & $\mathrm{C}$ & $2.35 \pm 0.14$ & $2.55 \pm 0.12$ & $2.88 \pm 0.02$ & $2.78 \pm 0.08$ & $2.56 \pm 0.24$ \\
\hline & MCS & $2.26 \pm 0.08$ & $2.20 \pm 0.17$ & $2.34 \pm 0.09^{* *}$ & $2.17 \pm 0.09^{* *}$ & $2.31 \pm 0.17$ \\
\hline \multirow{2}{*}{ ADP } & $\mathrm{C}$ & $1.01 \pm 0.041$ & $1.10 \pm 0.080$ & $1.01 \pm 0.08$ & $1.16 \pm 0.11$ & $0.942 \pm 0.045$ \\
\hline & MCS & $0.91 \pm 0.037$ & $0.69 \pm 0.062^{* *}$ & $0.72 \pm 0.08 \|$ & $0.81 \pm 0.04 \|$ & $0.979 \pm 0.131$ \\
\hline \multirow[t]{2}{*}{ AMP } & $\mathrm{C}$ & $0.079 \pm 0.009$ & $0.086 \pm 0.013$ & $0.082 \pm 0.015$ & $0.103 \pm 0.020$ & $0.098 \pm 0.018$ \\
\hline & MCS & $0.098 \pm 0.012$ & $0.129 \pm 0.012 \|$ & $0.117 \pm 0.010 \|$ & $0.142 \pm 0.030$ & $0.126 \pm 0.023$ \\
\hline \multirow[t]{2}{*}{$\mathrm{ATP}+\mathrm{ADP}+\mathrm{AMP}$} & $\mathrm{C}$ & $3.36 \pm 0.13$ & $3.75 \pm 0.15$ & $4.03 \pm 0.19$ & $4.04 \pm 0.20$ & $3.61 \pm 0.24$ \\
\hline & MCS & $3.27 \pm 0.08$ & $3.02 \pm 0.15 \|$ & $3.17 \pm 0.14^{* *}$ & $3.12 \pm 0.07^{* *}$ & $3.42 \pm 0.24$ \\
\hline Energy§ & $\mathrm{C}$ & $0.805 \pm 0.024$ & $0.825 \pm 0.008$ & $0.853 \pm 0.006$ & $0.832 \pm 0.010$ & $0.837 \pm 0.015$ \\
\hline Charge & MCS & $0.829 \pm 0.008$ & $0.831 \pm 0.008$ & $0.851 \pm 0.007$ & $0.823 \pm 0.016$ & $0.818 \pm 0.015$ \\
\hline Energy§ & $\mathrm{C}$ & $24.14 \pm 2.42$ & $35.05 \pm 3.61$ & $35.32 \pm 1.33$ & $36.32 \pm 2.71$ & $30.57 \pm 1.78$ \\
\hline Reserve & MCS & $22.97 \pm 2.10$ & $21.58 \pm 0.899$ & $25.11 \pm 1.96^{* *}$ & $25.62 \pm 1.79^{* *}$ & $24.08 \pm 2.20 \|$ \\
\hline \multirow[t]{2}{*}{ NAD/NADH } & C & $1036 \pm 145$ & $1005 \pm 146$ & $1025 \pm 140$ & $990 \pm 90$ & $1650 \pm 299$ \\
\hline & MCS & $1356 \pm 214$ & $1394 \pm 104 \|$ & $1279 \pm 104$ & $1277 \pm 175$ & $1425 \pm 201$ \\
\hline \multicolumn{7}{|l|}{ No. studied } \\
\hline \multirow{2}{*}{\multicolumn{2}{|c|}{$\begin{array}{l}\text { Control } \\
\text { MCS }\end{array}$}} & 6 & 6 & 6 & 6 & 6 \\
\hline & & 7 & 9 & 7 & 5 & 5 \\
\hline
\end{tabular}

* Control.

$\dagger$ Prior MCS.

$\ddagger(\mathrm{ATP}+1 / 2 \mathrm{ADP})-(\mathrm{ATP}+\mathrm{ADP}+\mathrm{AMP})$.

$\S \mathrm{PCr}+\mathrm{ADP}+2$ (glucose $+\mathrm{ATP})+2.9$ glycogen.

$\| p<0.05$.

I $p<0.001$.

$* * p<0.01$.

\section{DISCUSSION}

Previous studies of the effects of mild intrauterine growth retardation and postnatal hypoglycemia on cerebral metabolism in dogs suggested that cerebral amino acids of the glutamate group were oxidized to maintain cerebral energy metabolism (7). In this prior and milder model of intrauterine growth retardation, birth weight was reduced $9 \%$ in contrast to the $23 \%$ reduction 
of fetal growth in the present study $(2,5)$. In the less severe model of intrauterine growth retardation, cerebral ATP, PCr, and energy charge were unaltered; while perturbations of the amino acids of the glutamate group suggested that this large cerebral pool of amino acids might be utilized to maintain energy production (7).

The present model extends the period of MCS to 5 days and results in more severe intrauterine growth retardation. The transient hypoglycemia in the newborn period at $3 \mathrm{~h}$ of age, together with a decrease in plasma FFA levels and an increase in alanine levels, is simlar to metabolic observations noted in hypoglycemic human newborn infants with intrauterine growth retardation (35). Although MCS may not parallel many of the features of human intrauterine growth retardation, the circulating fuel profile and fetal weight reduction suggest that this is a reasonable animal model of the human disease.

In the present model it is difficult to separate the effects of previous maternal canine starvation, fasting during the neonatal period, and the additional factor of neonatal hypoglycemia on the alteration of brain metabolism. The use of multiple fasted age groups in controls and MCS can control for the effects of various periods of neonatal fasting. Nonetheless the perturbations of brain metabolites due to MCS alone noted at the time of birth were minimal and did not demonstrate alterations of fetal energy status, as expressd by CPr, ATP levels, or the energy charge and energy reserve. The predominant changes in cerebral energy metabolism in MCS pups occurs during or after the period of lowered blood glucose concentration at $3 \mathrm{~h}$ of age. Thus hypoglycemia, although transient, and a delayed recovery from hypoglycemia may be the major factors that affect neonatal cerebral energy metabolism. This does not exclude the possibilities that the observed perturbations were modified (increased or decreased) by the effects of intrauterine growth retardation.

At $3 \mathrm{~h}$ of age MCS pups have lower levels of circulating and brain glucose levels. When peripheral glucose levels decline, brain levels will be reduced as a new equilibrium is attained. This is due in part to depletion of free cellular glucose by way of cerebral metabolic pathways. Brain glucose may flow to glycogen synthesis or to the glycolytic pathway. Normal dogs usually have an increment of cerebral glycogen stores after birth (7). This was apparent among control pups but not in pups with intrauterine growth retardation. Because brain glucose, UDP-glucose, and F6P were lower among MCS pups, especially at $3 \mathrm{~h}$ of age, while glycogen content did not increase between birth and this time, glucose must have entered the glycolytic pathway. To facilitate this pathway, enhanced activity of phosphofructokinase may have pulled glucose in the direction of glycolysis. This enzyme has been known to be a rate limiting, regulatory enzyme during periods of cerebral anoxia or ischemia. Although glucose supply is diminished during total ischemia, there remains strong evidence that this regulatory enzyme is activated $(10,12,13)$. Despite an apparent increase in phosphofructokinase activity at $3 \mathrm{~h}$, the redox state data demonstrate a more oxidized cytoplasm. This suggests that the rate of oxidation by way of glycolysis was reduced compared with control pups fasted for $3 \mathrm{~h}$. Recovery at 6,9 , and $24 \mathrm{~h}$ following hypoglycemia, demonstrated by the normal cytoplasmic redox state and normal glucose levels, may be due in part to the continuation of augmented phosphofructokinase activity beyond $3 \mathrm{~h}$ of age.

In the lower segment of the glycolytic pathway, cerebral lactate levels appeared to be lower in MCS pups at 3 and $6 \mathrm{~h}$ of age despite similar or increased blood levels of lactate among MCS pups at these times (5). Lactate may function as cerebral cortical fuel in many newborn species, including man (14-16). Other studies among newborn beagles by our group (18) and Gregoire et al. (17) have demonstrated release of lactate from the brain. The pups releasing lactate were beagles and were also very young compared with studies demonstrating lactate uptake. During periods of hypoglycemia in newborn beagles born to starved mothers, less cerebral lactate is released into the systemic circu- lation than during normoglycemia (18). In the presence of similar glucose arteriovenous differences, these data suggest that lactate oxidation functions as an alternate cerebral fuel. The observed decline of cerebral lactate levels in MCS pups compared to agematched controls (in the presence of similar blood lacate levels: $1.76 \pm 0.2$ versus $1.72 \pm 0.2$ at $3 \mathrm{~h}$ ) suggests that lactate oxidation in the Krebs cycle may be augmented at this time. The alteration of the redox state, together with activation of cerebral pyruvate dehydrogenase, could explain these findings.

Additional alternate fuels that may enter the pathway of oxidative metabolism by transamination reactions are the amino acids of the glutamate group. Increased cerebral aspartate and diminished glutamine and alanine have been reported before in hypoglycemic neonatal dogs and in hypoglycemic newborn and adult rats $(7,12,19-22)$. This large pool of cerebral cortical amino acids related to glutamate exceeds the amount of cerebral glycogen by approximately 6-fold and may be more readily mobilized. These endogenous cerebral amino acids probably function as a major source of oxidizable substrates during periods of diminished circulating glucose levels. Similar observations of increased transamination of these amino acids have been noted in the undisturbed state by NMR spectroscopy during hypoglycemia (23).

In addition to circulating hypoglycemia at $3 \mathrm{~h}$ of age, MCS pups also demonstrated a transient decline of FFA and a more persistent reduction of plasma glycerol levels (5). Both fuels pobably have little effect on cerebral energy metabolism. Glycerol in particular has not been demonstrated to be taken up by the newborn brain in mice, subhuman primates, or man $(3,16,24)$.

Despite apparent increased rates of phosphofructokinase activity and oxidation of alternate fuels in MCS pups during and after hypoglycemia, cerebral energy production appeared to be severely diminished. In adult rats with mild to moderate hypoglycemia, cerebral energy metabolism may be unaltered as ATP levels do not decline (20). Furthermore cerebral oxygen consumption is not reduced in hypoglycemic dogs despite a marked decline in the total cerebral utilization of glucose (15). It has been hypothesized that augmented oxidation of endogenous cerebral substrates maintains the energy status of the brain. However, as hypoglycemia becomes more severe, adult rats demonstrate a decline in cerebral cortical ATP levels (20). Thus, even though alternate fuel oxidation is increased, energy production has been noted not to be maintained in other models of hypoglycemia and possibly not in the present newborn dog model as well.

Endogenous fuel oxidation appears to be enhanced in the hypoglycemic fasted newborn dog following MCS compared to the time matched control dogs. Nonetheless, the cerebral energy status during and following the decline of blood glucose values is adversely affected. At $3 \mathrm{~h}$ the cerebral cortex of the MCS pups is in a more oxidated state (less NADH production) as evidenced by the redox ratio and perhaps by the altered oxaloacetate to malate ratio. Furthermore the alterations of $\mathrm{PCr}$ and the adenine nucleotides during both this time and later during recovery also suggest decreased energy production. Similar observations were noted simultaneously in hepatic tissue from these same pups, as glycolytic flux was thought to be accelerated, while hepatic ATP levels were significantly decreased following MCS and hypoglycemia (5).

This energy deficiency state may not be due only to diminished glucose availability. Brain glycogen content was not mobilized during the early neonatal period (3-9 h). Furthermore although there were alterations of the glutamate pool of amino acids, this source of potentially oxidizable substates was not exhausted to very low levels as reported in adult models of hypoglycemia (12, 21). These data suggest that, in addition to diminished availability of circulating glucose, the mobilization and/or oxidation of endogenous cerebral fuels were also insufficient to maintain cerebral energy production. Although there was evidence for increased phosphofructokinase activity and transamination of 
the glutamate amino acid pool, the augmented activity of these pathways was not sufficient to support neonatal cerebral oxidative metabolism.

Hypoglycemia was a transient event present only at $3 \mathrm{~h}$ of age. Thereafter systemic and brain glucose concentrations increased to control values. Nonetheless cerebral ATP remained low at 6 and $9 \mathrm{~h}$. The total adenine nucleotide pool and brain glutamine and malate levels also remained lower than control values. Similar observations of a delayed cerebral metabolite recovery from insulin-induced hypoglycemia, despite sufficient blood glucose levels, have been noted in adult dogs, rats, and mice (12, $22,23,25)$. Following administration of glucose, the neurological status of the animal improves rapidly; however, cerebral cortical levels of ATP, malate, and glutamine do not immediately return to control values $(12,22,25)$. This may be related to cell injury, diminished membrane transport, reduced capillary bed recruitment, and/or depletion of the four carbon precursors of the Krebs cycle (glucose carbons are the major precurser for both Krebs cycle intermediates and the glutamine pool).

The poor neurodevelopmental outcome among human infants with intrauterine growth retardation is a complex result of the effects of poor intrauterine growth and any additional central nervous system injury resulting from hypoglycemia (26). Many growth-retarded newborn infants without hypoglycemia will have learning disabilities, while those with symptomatic hypoglycemia have a much poorer neurological prognosis. A combination of intrauterine growth retardation and hypoglycemia, as examined in the present animal model, may adversely affect the neonatal brain's ability to maintain oxidative metabolism. Alterations of the brain's energy metabolism during critical periods of brain growth and development may have serious consequences for future neurointellectual function.

Acknowlegments. The author expresses appreciation to $\mathrm{Mr}$. George Campbell and Ms. Sharon Morton for technical assistance and to Ms. Sandra Hartman and Ms. Claire Svet for preparation of the manuscript.

\section{REFERENCES}

Girard J, Ferre' P, Gilbert M, Kervan F, Assan R, Marliss E 1977 Fetal metabolic response to maternal fasting in the rat. Am J Physiol 232:E456461

2. Kliegman R, Miettinen E, Adam P 1981 Fetal and neonatal responses to maternal canine starvation: circulating fuels and neonatal glucose production. Pediatr Res 15:945-951

3. DeLeeuw R, Devris I 1976 Hypoglycemia in small for dates newborn infants. Pediatrics 58:18-25

4. Mestyan J, Soltesz G, Schultz K, Horwath M 1975 Hyperaminoacidemia due to the accumulation of gluconeogenic amino acid precursors in hypoglycemic small for gestational age infants. J Pediatr 87:409-415

5. Miettinen E, Kliegman R, Tserng K 1983 Fetal and neonatal responses to extended maternal canine starvation. I. Circulating fuels and glucose and lactate turnover. Pediatr Res 17:634-638

6. Chase HP, Marlow, RA, Dabiere CS, Welch NH 1973 Hypoglycemia and brain development. Pediatrics 52:513-520

7. Kliegman R, Miettinen E, Rolin W, Adam P 1981 Fetal and neonatal cerebral metabolism following maternal canine starvation. Pediatr Res 15:859-865

8. Miettinen E, Kliegman R 1983 Fetal and neonatal responses to extended maternal canine starvation. II. Fetal and neonatal liver metabolism. Pediatr Res 17:639-644

9. Schreiber R 1981 Developmental changes in brain glucose, glycogen, phosphocreatine and ATP levels in DBA/2J and C57BL/6J mice and audrogenic seizures. J Neurochem 37:655-666

10. Vannucci R, Duffy T 1970 Influence of birth on carbohydrate and energy metabolism in rat brain. Am J Physiol 226:933-940

11. Vannucci R, Nardis E, Vannucci S 1980 Cerebral metabolism during hypoglycemia and asphyxia in newborn dogs. Biol Neonate 38:276-286

12. Agardh C, Folbergrova J, Siesjo B 1978 Cerebral metabolic changes in profound insulin induced hypoglycemia and the recovery period following glucose administration. J Neurochem 31:1135-1142

13. Siesjo BK 1978 Brain Energy Metabolism. John Wiley \& Sons, Chichester

14. Fernandez J, Berger R, Smit G 1984 Lactate as a cerebral metabolic fuel for glucose-6-phosphatase deficient children. Pediatr Res 18:335-339

15. Hernandez M, Vannucci R, Salcedo A, Brennan R 1980 Cerebral blood flow and metabolism during hypoglycemia in newborn dogs. J Neurochem 3:622 628

16. Levitsky L, Fisher D, Paton J, Delannoy C 1977 Fasting plasma levels of glucose, acetoacetate, D- $\beta$-hydroxybutyrate, glycerol, and lactate in the baboon infant: correlation with cerebral uptake of substrates and oxygen Pediatr Res 11:298-302

17. Gregoire N, Gjedde A, Plum F, Duffy $\Upsilon 1978$ Cerebral blood flow and cerebral metabolic rates for oxygen, glucose and ketone bodies in newborn dogs. $\mathrm{J}$ Neurochem 30:63-69

18. Kliegman R, Miettinen E, Sutton A, Patel M 1982 Neonatal substrate A-V differences following maternal canine starvation. Pediatr Res 16:113A

19. Davis J, Himwich W, Pederson V 1970 Hypoglycemia and developmental changes in free amino acids of rat brain. J Appl Physiol 29:219-222

20. Lewis L, Ljunggren B, Ratcheson R, Siesjo B 1974 Cerebral energy state in insulin induced hypoglycemia related to blood glucose levels. $J$ Neurochem 23:673-679

21. Norberg K, Siesjo B 1976 Oxidative metabolism of cerebral cortex of the rat in severe insulin induced hypoglycemia. J Neurochem 26:345-352

22. Tews J, Carter S, Stone W 1965 Chemical changes in the brain during insulin hypoglycemia and recovery. J Neurochem 12:679-693

23. Behar K, den Hollander J, Petroff O, Hetherington H, Prichard J, Shulman R The effect of hypoglycemic encephalopathy upon amino acids, high energy phosphates and $\mathrm{pHi}$ in the rat brain in vivo detection by sequential $\mathrm{H}$ and $\mathrm{P}$ NMR spectroscopy. J Neurochem (in press)

24. Holowach-Thurston J, Hauhart R, Dirgo J 1981 Effects of a single therapeutic dose of glycerol on cerebral metabolism in brains of young mice: possible increase in brain glucose transport and glucose utilization. $J$ Neurochem 36:830-836

25. Gorell J, Law M, Lowry O, Ferrendeli J 1977 Levels of cerebral cortical glycolytic and citric acid metabolites during hypoglycemic stupor and its reversal. J Neurochem 29:187-191

26. Koivisto M, Blanco-Sequeiros M, Krause U 1972 Neonatal symptomatic and asymptomatic hypoglycaemia: a follow-up study of 151 children. Dev Med Child Neurol 14:603-614 